\title{
Arrays of flow channels with heat transfer embedded in conducting walls
}

\author{
A.Bejan ${ }^{1}$, A. Almerbati ${ }^{1}$, S. Lorente ${ }^{2}$, A.S. Sabau ${ }^{3}$, J. W. Klett ${ }^{3}$, \\ ${ }^{1}$ Department of Mechanical Engineering and Materials Science, Duke University, \\ Durham, NC 27708-0300, U.S.A \\ ${ }^{2}$ Université de Toulouse, INSA, 135 Avenue de Rangueil, \\ 31077 Toulouse, France \\ ${ }^{3}$ Oak Ridge National Laboratory, Oak Ridge, TN 37830, USA
}

\begin{abstract}
Here we illustrate the free search for the optimalgeometry of flow channel cross-sections that meet two objectives simultaneously: reduced resistances to heat transfer and fluid flow. The element cross section and the wall material are fixed, while the shape of the fluid flow opening, or the wetted perimeter is free to vary. Two element cross sections are considered, square and equilateral triangular. We find that the two objectives are best met when the solid wall thickness is uniform, i.e., when the wetted perimeters are square and triangular, respectively. We also consider arrays of square elements and triangular elements, on the basis of equal mass flow rate per unit of array cross sectional area. The conclusion is that the array of triangular elements meets the two objectives better than the array of square elements.
\end{abstract}

Keywords: Constructal design, heat exchanger, array of channels, flow channel, square cross section, triangular cross section, multiple objectives, morphing. 


\section{Nomenclature}

$\mathrm{A}_{\mathrm{s}, \mathrm{f}} \quad$ cross sectional area, $\mathrm{m}^{2}$

$\mathrm{c}_{\mathrm{P}} \quad$ specific heat at constant pressure, $\mathrm{J} \mathrm{kg}^{-1} \mathrm{~K}^{-1}$

$\mathrm{D}_{\mathrm{h}} \quad$ hydraulic diameter, $\mathrm{m}$

f friction factor

$\overline{\mathrm{h}} \quad$ effective heat transfer coefficient, $\mathrm{W} \mathrm{m}{ }^{-2} \mathrm{~K}^{-1}$

$\mathrm{k}_{\mathrm{s}, \mathrm{f}} \quad$ thermal conductivity, $\mathrm{W} \mathrm{m} \mathrm{m}^{-1} \mathrm{~K}^{-1}$

$\tilde{\mathrm{k}}$ thermal conductivity ratio $\tilde{\mathrm{k}}=\mathrm{k}_{\mathrm{s}} / \mathrm{k}_{\mathrm{f}}$

$\mathrm{L}_{\mathrm{c}} \quad$ distance between centers, Fig. 1c, $\mathrm{m}$

$\mathrm{L}_{\mathrm{s}, \mathrm{t}} \quad$ side length, $\mathrm{m}$

$\mathrm{L}_{\mathrm{x}} \quad$ length of channel, $\mathrm{m}$

$\dot{\mathrm{m}} \quad$ mass flow rate, $\mathrm{kg} \mathrm{s}^{-1}$

$\dot{\mathrm{m}}^{\prime \prime} \quad$ mass flow rate per unit area of array cross section, $\mathrm{kg} \mathrm{s}^{-1} \mathrm{~m}^{-2}$

$\mathrm{N} \quad$ number of heat transfer units

$\mathrm{Nu} \quad$ Nusselt number

$\mathrm{p} \quad$ wetted perimeter, $\mathrm{m}$

Po Poiseuille constant

Pr Prandtl number

$\mathrm{R} \quad$ radius of rounded corner, Fig. $1 \mathrm{c}, \mathrm{m}$

$\operatorname{Re}_{D_{\mathrm{h}}} \quad$ Reynolds number

$\mathrm{R}_{\mathrm{f}} \quad$ dimensionless fluid flow resistance

$\mathrm{R}_{\mathrm{th}} \quad$ dimensionless thermal resistance

$\mathrm{T}_{\mathrm{w}} \quad$ external walls temperature, $\mathrm{K}$ 


$\begin{array}{ll}\mathrm{T}_{\text {in }} & \text { inlet temperature, } \mathrm{K} \\ \mathrm{T}_{\text {out }} & \text { outlet temperature, } \mathrm{K} \\ \mathrm{U} & \text { average fluid velocity, } \mathrm{m} \mathrm{s}^{-1} \\ \text { Greek } & \text { symbols } \\ \phi & \text { dimensionless flow area, Eq. (6) } \\ \psi & \text { dimensionless perimeter, Eq. (6) } \\ v & \text { kinematic viscosity, } \mathrm{m}^{2} \mathrm{~s}^{-1} \\ \rho & \text { fluid density, } \mathrm{kg} \mathrm{m}^{-3} \\ \text { Subscripts } \\ \mathrm{f} & \text { fluid } \\ \mathrm{s} & \text { solid } \\ \mathrm{s} & \text { square element } \\ \mathrm{t} & \text { triangular element }\end{array}$

\section{Introduction}

The shape of the flow channel cross-section plays an important role in the flow and heat transfer performance of heat exchangers. The main purpose of optimizing the shape of the flow channel is to simultaneously enhance the heat transfer rate and to reduce the pumping power requirement. Recent studies have focused on optimizing the flow architecture in order to enhance the heat transfer rate [1-6]. Several studies have demonstrated the effect of the wetted perimeter shape on the flow performance [7-14]. Additionally, the longitudinal configuration of the flow channel such as zigzag, curvy, step [15], single-layer, double-layer, tapered [16], wavy [17] and converting channels [18] for the same cross-sectional shape was investigated and 
compared with the conventional straight channel with uniform cross-sectional shape.

On this background, the comparison between different cross-sectional shapes to accomplish the two objectives simultaneously, lower pressure drop along the flow channel and higher heat transfer rate between the fluid flow and the heated wall, is a new point of view that deserves to be investigated. In this study we seek to decrease simultaneously the longitudinal flow resistance and the transversal thermal resistance for the square, circle and triangle cross-section channels. The work is based on two analytical models, i.e., scale analysis, and computational fluid dynamics (CFD) models.

\section{Square element}

We begin with a square array, with these known features:side $L_{s}$, loop cross section $L_{s}^{2}$, flow cross section $A_{f}$, solid cross section $A_{s}=L_{s}^{2}-A_{f}$, known fluid properties: $\left(k_{f}, \mu, v\right)$, and solid properties: $\left(\mathrm{k}_{\mathrm{s}}\right.$, etc.).The search is for the best shape of the wetted perimeter, such that two objectives are met at the same time:small transversal thermal resistance between the fluid stream and the square perimeter, and small longitudinal flow resistance, $\Delta \mathrm{P} / \dot{\mathrm{m}}$. The mass flow rate $\dot{\mathrm{m}}$ is fixed; it is the stream allocated to one element with square cross section, as shown in Fig. 1. The shape of the wetted perimeter varies between the two extremes shown in the upper part of Fig. 1: (a) square flow cross section, and (b) round flow cross section.

2.1 Flow resistance. Assume that the flow is laminar and fully developed (Poiseuille). This means that the longitudinal flow resistance is [1]

$$
\frac{\mathrm{dP}}{\mathrm{dx}}=\mathrm{f} \frac{4}{\mathrm{D}_{\mathrm{h}}} \frac{1}{2} \rho \mathrm{U}^{2}
$$

where $\mathrm{U}$ is the average fluid velocity,

$\mathrm{D}_{\mathrm{h}}$ is the hydraulic diameter,

$$
\mathrm{U}=\frac{\dot{\mathrm{m}}}{\rho \mathrm{A}_{\mathrm{f}}}
$$




$$
\mathrm{D}_{\mathrm{h}}=\frac{4 \mathrm{~A}_{\mathrm{f}}}{\mathrm{p}}
$$

$p$ is the wetted perimeter, $f$ is the friction coefficient

$$
\mathrm{f}=\frac{\mathrm{Po}}{\operatorname{Re}_{\mathrm{D}_{\mathrm{h}}}}, \quad \operatorname{Re}_{\mathrm{D}_{\mathrm{h}}}=\frac{\mathrm{UD}_{\mathrm{h}}}{\mathrm{v}}
$$

and Po is the Poiseuille constant. The extreme values of Po for cases (a) and (b) in Fig. 1 are [1], respectively:

$$
\mathrm{Po}_{\mathrm{a}}=14.2 \quad \mathrm{Po}_{\mathrm{b}}=16
$$

The effect of the shape of the wetted perimeter is brought into the analysis by introducing the dimensionless factors $\phi$ and $\psi$ :

$$
\begin{array}{ll}
\mathrm{A}_{\mathrm{f}}=\phi \mathrm{L}_{\mathrm{s}}^{2}, & \phi<1 \\
\mathrm{p}=\psi 4 \mathrm{~L}_{\mathrm{s}}, & \psi<1
\end{array}
$$

Combining Eqs. (1) - (6), we arrive at the dimensionless fluid flow resistance

$$
\mathrm{R}_{\mathrm{f}}=\frac{\mathrm{dP} / \mathrm{dx}}{\dot{\mathrm{m} v} / \mathrm{D}_{\mathrm{h}}^{2} \mathrm{~A}_{\mathrm{f}}}=2 \mathrm{Po} \frac{\psi^{2}}{\phi^{3}}
$$

One objective is to decrease $R_{f}$. We know already that if this is the only objective then the best cross section is (b), the round cross section. In this study, however, there is also a second objective (to minimize the transversal thermal resistance), and for this reason we continue with the general case where $\phi$ and $\psi$ may vary.

When the rule of morphing (a) into (b) is simple, as in Fig. 1 where all the corners are identical, there is a relation between $\phi$ and $\psi$. To see this, assume that $\phi$ is specified, therefore $\phi_{\mathrm{a}}=\phi_{\mathrm{b}}=\phi$. Next, for the round perimeter (b) we have $\mathrm{p}_{\mathrm{b}}=\pi \mathrm{D}_{\mathrm{b}}$ and $\mathrm{A}_{\mathrm{b}}=(\pi / 4) \mathrm{D}_{\mathrm{b}}^{2}$, from which we deduce 


$$
\psi_{\mathrm{b}}=\frac{\pi^{1 / 2}}{2} \phi^{1 / 2}
$$

In case (a), the solid cross section is the same as in case (b), but $\mathrm{p}_{\mathrm{a}}=4 \mathrm{~L}_{\mathrm{a}}$ and $\mathrm{A}_{\mathrm{a}}=\mathrm{L}_{\mathrm{a}}^{2}$, therefore

$$
\psi_{\mathrm{a}}=\phi^{1 / 2}
$$

Another factor that could have been varied is the ratio $\mathrm{R} / \mathrm{L}_{\mathrm{c}}$ (i.e., case c) while keeping the minimum wall thicknessfixed. Varying the radius of curvature was not considered as both the dimensionless fluid flow resistance and thermal resistancewould fall within the limits given by cases (a) and (b). To draw case (c), we assumethat the radius of the rounded corners is $\mathrm{R}=$ $0.1 \mathrm{~L}_{\mathrm{c}}$, so that $\mathrm{p}_{\mathrm{c}}=4 \mathrm{~L}_{\mathrm{c}}+2 \pi \mathrm{R}$ and $\mathrm{A}_{\mathrm{c}}=\mathrm{L}_{\mathrm{c}}^{2}+4 \mathrm{RL}_{\mathrm{c}}+\pi \mathrm{R}^{2}$, therefore

$$
\psi_{\mathrm{c}}=0.967 \phi^{1 / 2}
$$

In summary, the values of $R_{f, a}, R_{f, b}$ and $R_{f, c}$ depend only on the assumed value for $\phi$. By varying $\phi$, the fluid cross-section varies in size while the area of the square solid is kept constant. These functions are plotted in Fig. 2. Note that case (b) exists when $\phi$ does not exceed the value that corresponds to the circle touching the sides of the square in Fig. 1 (b):

$$
\phi_{\max , \mathrm{b}}=\frac{(\pi / 4) \mathrm{L}_{\mathrm{s}}^{2}}{\mathrm{~L}_{\mathrm{s}}^{2}}=0.785
$$

Similarly, case (c) exists when $\phi$ does not exceed 0.994 .

2.2 Thermal resistance. The thermal objective of the flow system can be simulated numerically for the model shown in Fig. 3. The system is a sufficiently long parallelepiped with a square cross section in which we can fit any of the drawings shown in Fig. 1. Each such drawing is characterized by its $\phi$ and $\psi$.

The fluid flow is laminar and fully developed, which means that the longitudinal velocity distribution $(\mathrm{u})$ does not vary from one $\mathrm{x}$ cut to another. The temperature field is also 
fullydeveloped, therefore the meniscus shape of the $\mathrm{T}$ distribution over the flow cross section does not vary from one $\mathrm{x}$ to another.

Assume that the long external walls of the parallelepiped are isothermal at $T_{\mathrm{w}}$, and that the average temperature of the fluid entering through the $\mathrm{x}=0$ end is $\mathrm{T}_{\mathrm{in}}$. Also assume that the mass flow rate (m) along the duct is specified. The continuity of heat flux at the solid-fluid interface (in the same plane as the cross section) requires

$$
\mathrm{k}_{\mathrm{s}} \frac{\partial \mathrm{T}}{\partial \mathrm{n}}=\mathrm{k}_{\mathrm{f}} \frac{\partial \mathrm{T}}{\partial \mathrm{n}}
$$

where $\mathrm{n}$ is the normal to the solid/fluid interface. Equation (12) reveals the role of $\tilde{\mathrm{k}}=\mathrm{k}_{\mathrm{s}} / \mathrm{k}_{\mathrm{f}}$ as a dimensionless parameter of the flow system. Another parameter is the fluid Prandtl number, $\operatorname{Pr}$, set equal to 1 , which is the order of magnitude of common fluids.

The overall thermal contact is measured between the outer surface of the system $\left(T_{w}\right)$ and the bulk temperature of the fluid in the channel. At the outlet, $x=L_{x}$, the bulk fluid temperature is $\mathrm{T}_{\text {out. }}$ The fluid temperature change from inlet to outlet is given by (Fig. 4) [1]

$$
\ln \frac{\mathrm{T}_{\mathrm{w}}-\mathrm{T}_{\text {in }}}{\mathrm{T}_{\mathrm{w}}-\mathrm{T}_{\text {out }}}=\frac{\overline{\mathrm{h}} \psi 4 \mathrm{~L}_{\mathrm{s}} \mathrm{L}_{\mathrm{x}}}{\dot{\mathrm{m} \mathrm{c}_{\mathrm{P}}}}
$$

where $4 \mathrm{~L}_{\mathrm{s}}$ is the perimeter of the square cross section, and $\overline{\mathrm{h}}$ is an effective (overall) heat transfer coefficient that accounts for the thermal contact between $T_{w}$ and the bulk temperature $T(x)$. Note that $T(x)$ increases from $T_{\text {in }}$ to $T_{\text {out. }}$ The right side of Eq. (13) is the number of heat transfer unitsof the fluid and solid system, which is defined as

$$
\mathrm{N}=\frac{\psi 4 \mathrm{~L}_{\mathrm{s}} \mathrm{L}_{\mathrm{x}} \overline{\mathrm{h}}}{\dot{\mathrm{m}} \mathrm{c}_{\mathrm{P}}}
$$

where $\psi 4 \mathrm{~L}_{\mathrm{s}}$ is the perimeter of contact, and $\mathrm{N}$ is greater when the thermal contact is stronger.

The non-isothermal flow COMSOL model was used to simulate the temperature field of 
the channel flow. An non-isothermal model is used forthe fluid flow and heat transfer, i.e., in which the fluid properties such as density and viscosity are temperature dependent. The fluid properties at the duct entrancearec ${ }_{P}=4192 \mathrm{~J} /(\mathrm{kgK}), \rho=999.7 \mathrm{~kg} / \mathrm{m}^{3}, \quad v=10^{-6} \mathrm{~m}^{2} / \mathrm{s}$.It is considered that $\dot{\mathrm{m}}_{0}=0.01 \mathrm{~kg} / \mathrm{s}$. The solid wall properties are $\mathrm{c}=475 \mathrm{~J} /(\mathrm{kgK}), \rho=7850 \mathrm{~kg} / \mathrm{m}^{3}$, $\mathrm{k}_{\mathrm{s}}=44.5 \mathrm{~W} /(\mathrm{mK})$. The flow regime is laminar as the Reynolds number $\left(\mathrm{Re}=\mathrm{UD}_{\mathrm{h}} / \mathrm{v}\right)$ does not exceed 2300. Here, $\mathrm{D}_{\mathrm{h}}$ is either the diameter of the cylinder or the hydraulic diameter of the fluid flow channel.

The governing equations for the non-isothermal 3-D flow are mass flow continuity, momentum and energy equations for the fluid in the duct plus the heat conduction equation for the solid wall [19]. The boundary conditions are as follows. At the inlet of the duct, a uniform temperature $\mathrm{T}_{\text {in }}(300 \mathrm{~K})$ is assumed and the mean velocity of the channel flow is specified as $\mathrm{U}=\dot{\mathrm{m}} / \rho \mathrm{A}_{\mathrm{f}}$. The entrance region for laminar pipe flow is calculated as $\mathrm{L}_{\mathrm{e}} / \mathrm{D}_{\mathrm{h}} \cong 0.06 \mathrm{Re}$, where $\mathrm{D}_{\mathrm{h}}$ is the hydraulic diameter. At the duct outlet, the pressure is constant and the heat conduction condition is $\mathrm{n} \cdot\left(\mathrm{k}_{\mathrm{f}} \nabla \mathrm{T}_{\mathrm{f}}\right)=0$. The no slip boundary condition $(\mathrm{u}=0)$ is applied on the side walls of the flow duct. A constant temperature boundary condition $(350 \mathrm{~K})$ is specified at the outer surfaces of the solid walls. Table 1 shows the computational results for one case: $\phi=$ 0.7 , in square arrays. The results show that the average temperature at the channel outlet becomes almost independent of the mesh size. Therefore, the mesh with $2 \times 10^{5}$ elements is used in this study because the computational results converge as the mesh is refined, i.e., the effect of the mesh on the computational results becomes negligible as the grid size is decreased beyond the $2 \times 10^{5}$ elements. 
Table 1. Mesh accuracy test.

\begin{tabular}{ccc}
\hline Number of elements & $\mathrm{T}_{\text {out,avg }}(\mathrm{K})$ & Difference (\%) \\
\hline 51,924 & 325.7256 & ----- \\
143,936 & 325.1887 & 0.165 \\
204,771 & 325.1928 & 0.0013 \\
311,025 & 325.1934 & 0.00018 \\
577,148 & 325.1938 & 0.00012 \\
\hline
\end{tabular}

In this numerical work, $\mathrm{N}$ is a measure of the degree of thermal contact, because it is proportional to the thermal conductance, cf. Eq. (14). The value of $\mathrm{N}$ is determined after numerical simulations, i.e., after calculating $\mathrm{T}_{\text {out }}$ and substituting this value (along with $\mathrm{T}_{\mathrm{w}}$ and $\mathrm{T}_{\text {in }}$ ) on theleft side of Eq. (13). There will be one $\mathrm{N}_{\mathrm{a}}(\phi)$ curve for the configuration of Fig.1a, one $\mathrm{N}_{\mathrm{b}}(\phi)$ for Fig. $1 \mathrm{~b}$ and another $\mathrm{N}_{\mathrm{c}}(\phi)$ for Fig. 1c. Keeping all the other parameters fixed, such as $\dot{\mathrm{m}}, \operatorname{Pr}, \tilde{\mathrm{k}}$ and $\mathrm{c}_{\mathrm{p}}$, and varying only $\phi$, it isexpectedthat $\mathrm{N}$ would decreasewhen the fluid flow dimensionless cross-section $(\phi)$ would increase.

Qualitatively, the overall thermal resistance $\mathrm{R}_{\text {th }}$ varies monotonically with the inverse of $\mathrm{N}$, as reported in Fig. 5,

$$
\mathrm{R}_{\mathrm{th}}=\frac{1}{\mathrm{~N}}
$$

The trend in Fig. 5 is the opposite of what it wasanticipated for $R_{f}$ in Fig. 2. This conflict is the basis for the two-objective search sketch in Fig. 6, which is obtained by eliminating $\phi$ between Figs. 2and 5. The search for better configurations [(a), (b), or (c)] is toward low- $\mathrm{R}_{\mathrm{f}}$ and low- $\mathrm{R}_{\text {th }}$ simultaneously. The better configuration is the one represented by a curve that comes closer to the origin, namely, the curve for the cross-section shown in Fig. 1a.

\section{Triangular element}


The analysis of the two-objective performance $\left(\mathrm{R}_{\mathrm{f}}, \mathrm{R}_{\mathrm{th}}\right)$ of a triangular array follows the same steps as in the preceding section. We focus on the extreme configurations, (a) triangular flow channel and (b) round flow channel, while the volume of wall material is fixed. The volume fraction occupied by the flow cross-section and channel is $\phi$. The flow cross-section and the wetted perimeterare $A_{t}=0.433 \phi \mathrm{L}_{\mathrm{t}}^{2}$ and $\mathrm{p}=\psi 3 \mathrm{~L}_{\mathrm{t}}$, such that $\psi_{\mathrm{a}}=\phi^{1 / 2}$ and $\psi_{\mathrm{b}}=3^{-3 / 4} \pi^{1 / 2} \phi^{1 / 2}$.

3.1Flow resistance. In place of Eq. (7) we obtain the following dimensionless fluid flow resistance

$$
\mathrm{R}_{\mathrm{f}}=\frac{\mathrm{dP} / \mathrm{dx}}{\dot{\mathrm{m} v} / \mathrm{D}_{\mathrm{h}}^{2} \mathrm{~A}_{\mathrm{f}}}=\frac{9}{8} \mathrm{Po} \frac{\psi^{2}}{\phi^{3}}
$$

The mass flow rate $\dot{\mathrm{m}}$ is fixed: In this case, $\dot{\mathrm{m}}$ is the stream allocated to one element with triangular cross section, Fig. 7. For the triangular duct, Fig. 7a, we substitute $\mathrm{Po}_{\mathrm{a}}=13.3$ and conclude that

$$
\mathrm{R}_{\mathrm{f}, \mathrm{a}}=14.96 \phi^{-2}
$$

Similarly, for the round cross section, Fig. $7 \mathrm{~b}$, where $\mathrm{Po}_{\mathrm{b}}=16$, we obtain

$$
\mathrm{R}_{\mathrm{f}, \mathrm{b}}=10.88 \phi^{-2}
$$

Equations (17) and (18) are plotted in Fig. 8, which shows that the flow resistance of the round channel is smaller than the resistance posed by the triangular channel. Note the similarity between Fig. 8 and Fig. 2. For the round cross section (b), the $\mathrm{R}_{\mathrm{f}}(\phi)$ curve ends at $\phi=0.6$, which represents the round duct that touches the triangular perimeter of the available space.

3.2 Thermal resistance. The effect of duct cross-sectional shape on the thermal resistance was determined by using the same numerical method as in section 2.2 and Fig. 2. The effective number of heat transfer units of the fluid-solid flow system that occupies the volume with triangular cross section and length $\mathrm{L}_{\mathrm{x}}$. The number of heat transfer units is based on the 
perimeter of the triangular cross section of the volume,

$$
\mathrm{N}=\frac{\psi 3 \mathrm{~L}_{\mathrm{t}} \mathrm{L}_{\mathrm{x}} \overline{\mathrm{h}}}{\dot{\mathrm{mc}} \mathrm{P}_{\mathrm{P}}}
$$

The inverse of $\mathrm{N}$ is regarded as a measure of the degree of thermal contact between the fluid and the external perimeter $\left(3 \mathrm{~L}_{t}\right)$, namely $\mathrm{R}_{\mathrm{th}}=\mathrm{N}^{-1}$, as shown in Fig. 9. The thermal resistance of the design with triangular flow cross section (a) is smaller than the thermal resistance of the design with round flow cross section.

Figures 8 and 9 were combined into the $\mathrm{R}_{\mathrm{f}}-\mathrm{R}_{\text {th }}$ plot shown in Fig. 10. For designs with two simultaneous objectives, small $\mathrm{R}_{\mathrm{f}}$ and small $\mathrm{R}_{\mathrm{th}}$, configuration (a) is better than configuration (b). This conclusion corresponds with what it was observed in Fig. 6 for square cross sections.

\section{Square array or triangular array?}

The similarities between the performance of the square elemental volume (Figs. 2, 5, 6) and the triangular elemental volume (Figs. 8-10) are evident. They invite the question of which cross-section would performs better, the square or equilateral triangle.

To answer this, first we recognize that the whole assembly is an array of many elements of the same kind (Fig. 11) in which the two fluid elements are arranged in a staggered manner and the heat exchanger is of counterflow type. The whole assembly has a purpose and a flow rate, which are the same regardless of the choice made for the shape of the elemental cross-section. In other words, the mass flow rate per unit of array cross sectional area, $\dot{\mathrm{m}}^{\prime \prime}$ is specified (fixed).

Second, in the study of square elements (Fig. 1), m was fixed because the size (the cross section) of the square element was fixed. The comparison was between three flow cross sectional shapes $(a, b, c)$, each carrying the same $\dot{\mathrm{m}}$. This is why the flow resistance defined in Eq. (7) depended on only $\phi, \psi$ and Po. The same is true for the flow resistance defined in Eq. 
(16) for the triangular element: the comparison was between Figs. 7a and $7 \mathrm{~b}$, and $\dot{\mathrm{m}}$ was the same for both configurations.

As we move to the whole arrays shown in Fig. 11, we note not only that $\dot{\mathrm{m}}^{\prime \prime}$ is the same for the two arrays, but also that the $\dot{m}$ that appears in Eq. (7) is not necessarily the same as the $\dot{m}$ in Eq. (16). For clarity, we compare the two arrays in terms of pressure drop, not flow resistances. For the square array, Eq. (7) can be rewritten as

$$
\left(\frac{\mathrm{dP}}{\mathrm{dx}}\right)_{\mathrm{s}} \frac{\mathrm{L}_{\mathrm{x}}^{2}}{\dot{\mathrm{m}}^{\prime \prime} \mathrm{v}}=\frac{2 \mathrm{Po}_{\mathrm{s}}}{\phi^{4} \tilde{\mathrm{L}}_{\mathrm{s}}^{2}}
$$

where $\tilde{\mathrm{L}}_{\mathrm{s}}=\mathrm{L}_{\mathrm{s}} / \mathrm{L}_{\mathrm{x}}$ is the dimensionless side of the square element, and $\mathrm{L}_{\mathrm{x}}$ is the length of the array in the flow direction.

For the triangular array, Eq. (16) can be rewritten as

$$
\left(\frac{d P}{d x}\right)_{t} \frac{L_{x}^{2}}{\dot{m}^{\prime \prime} v}=\frac{27}{8} \frac{P o_{t}}{\phi^{4} \tilde{L}_{t}^{2}}
$$

where $\tilde{\mathrm{L}}_{\mathrm{t}}=\mathrm{L}_{\mathrm{t}} / \mathrm{L}_{\mathrm{x}}$ is the dimensionless side of the triangular element. Dividing Eqs. (20) and (21), and recalling $\mathrm{Po}_{\mathrm{s}}=14.2$ and $\mathrm{Po}_{\mathrm{t}}=13.3$, we obtain

$$
\frac{(\mathrm{dP} / \mathrm{dx})_{\mathrm{s}}}{(\mathrm{dP} / \mathrm{dx})_{\mathrm{t}}}=0.633\left(\frac{\mathrm{L}_{\mathrm{t}}}{\mathrm{L}_{\mathrm{s}}}\right)^{2}
$$

The ratio $\mathrm{L}_{\mathrm{t}} / \mathrm{L}_{\mathrm{s}}$ is a degree of freedom in the drawing shown in Fig. 11:

(i) If the sides of the elements are equal, $\mathrm{L}_{t}=\mathrm{L}_{\mathrm{s}}$, then the pressure drop along the square array is 36.7 percent smaller than along the triangular array.

(ii) If the cross sectional areas of the elements are equal, $\mathrm{L}_{\mathrm{s}}^{2}=\left(3^{1 / 2} / 4\right) \mathrm{L}_{\mathrm{t}}^{2}$, then the right side of Eq. (22) is equal to 1.461. In this case, the pressure drop along the triangular array is one third smaller than along the square array. 
The thermal resistances of the two arrangements based on square and triangular crosssections can also be compared on an equal basis. To start with, as noted already en route to Eq. (15), the thermal resistance of one element is large when $\mathrm{N}$ is small. The relation between thermal resistance and $1 / \mathrm{N}$ becomes a proportionality in the limit $\mathrm{N} \ll<1$. This can be shown from Eq. (13), after writing $\mathrm{N}$ for the right hand side, and $\Delta \mathrm{T}=\mathrm{T}_{\mathrm{w}}-\mathrm{T}_{\mathrm{in}}$, and also $\mathrm{q}=\dot{\mathrm{mc}}_{\mathrm{P}}\left(\mathrm{T}_{\text {out }}-\right.$ $T_{\text {in }}$, where $q$ is the total heat transfer rate from the element of length $L_{x}$ to the stream $\dot{m}$ allocated to that element. In the limit $\mathrm{N}<<1$, Eq. (13) becomes

$$
\frac{\Delta \mathrm{T}}{\mathrm{q} / \dot{\mathrm{mc}} \mathrm{P}}=\frac{1}{\mathrm{~N}}
$$

and, after returning to the notation of Eq. (13),

$$
\left(\frac{\Delta \mathrm{T}}{\mathrm{q}}\right)_{\mathrm{s}}=\frac{1}{\overline{\mathrm{h}}{ }_{\mathrm{s}} \psi 4 \mathrm{~L}_{\mathrm{s}} \mathrm{L}_{\mathrm{x}}}
$$

The corresponding formula for the triangular element, derived from Eq. (19), is

$$
\left(\frac{\Delta T}{q}\right)_{t}=\frac{1}{\bar{h}_{t} \psi 3 L_{t} L_{x}}
$$

Dividing Eq. (24) and (25), we arrive at the ratio of the two thermal resistances,

$$
\frac{(\Delta \mathrm{T} / \mathrm{q})_{\mathrm{s}}}{(\Delta \mathrm{T} / \mathrm{q})_{\mathrm{t}}}=\frac{3}{4} \frac{\overline{\mathrm{h}}_{\mathrm{t}}}{\overline{\mathrm{h}}_{\mathrm{s}}} \frac{\mathrm{L}_{\mathrm{t}}}{\mathrm{L}_{\mathrm{s}}}
$$

Next, for fully developed laminar flow in channels with constant temperature [as in Eq. (13)], we have from Ref. [1], Table 3.2,

$$
\mathrm{Nu}_{\mathrm{s}}=\frac{\overline{\mathrm{h}}_{\mathrm{s}} \mathrm{D}_{\mathrm{h}, \mathrm{s}}}{\mathrm{k}_{\mathrm{f}}} \cong 2.89 \quad \mathrm{Nu}_{\mathrm{t}}=\frac{\overline{\mathrm{h}}_{\mathrm{t}} \mathrm{D}_{\mathrm{h}, \mathrm{t}}}{\mathrm{k}_{\mathrm{f}}} \cong 2.35
$$

where $D_{h, s}=\psi L_{s}$ and $D_{h, t}=\psi 3^{-1 / 2} L_{t}$, cf. Table 3.1 in Ref. [1]. 
The right side of Eq. (26) turns out to be equal to 1.056, independently of the choice of $\mathrm{L}_{\mathrm{t}} / \mathrm{L}_{\mathrm{s}}$. In conclusion, from a thermal contact standpoint, the triangular array (Fig. 7a) is 5.3 percent superior to the square array (Fig. 1a).

\section{Discussion and Conclusions}

In this article we illustrated the search for optimum cross-section of the flow in an assembly with identical array of tubes in counterflow with two objectives at the same time: reduced fluid flow resistance and reduced heat transfer resistance. We performed the scale analysis for individual elements (pipe flow). The fluid flow and heat transfer was simulated using a 2D model. The element cross sections considered in this study were square, circular, and equilateral triangular. The element wall material was fixed, while the shape and length of the wetted perimeter of the flow channel could vary.

For the square elements, we found that the geometry that serves the two objectives best is the one with constant wall thickness, i.e., square wetter perimeter (Fig. 1a). The design with circular wetted perimeter (Fig. 1b) is the worst. The designs with wetted perimeters shaped as squares with rounded corners are in between.It was also found tothat the triangular wetted perimeter cross-section (Fig. 7a) outperforms the one with circular flow cross section (Fig. 7b).

Important and interesting is the comparison between the two arrays consisting of square and triangular elements (Fig. 11). The comparison is done on the basis of a specified fluid mass flow rate per unit of array cross sectional area, such that the ratio $L_{s} / L_{t}$ is a degree of freedom. We considered two such ratios, $\mathrm{L}_{\mathrm{s}} / \mathrm{L}_{\mathrm{t}}=1$, and $\mathrm{L}_{\mathrm{s}} / \mathrm{L}_{\mathrm{t}}=3^{1 / 4} / 2$. In summary, the array of triangular channels meets the two objectives better than the array of square channels.

Acknowledgements. This work was performed for the project "Freeform Heat Exchangers for Binary Geothermal Power Plants" sponsored by the Geothermal Technologies Program, Office of 
Energy Efficiency and Renewable Energy, U.S. Department of Energy under contract DE-AC0500OR22725, Oak Ridge National Laboratory, managed and operated by UT-Battelle, LLC.This research was supported by the Oak Ridge National Laboratory through DOE contract \#4000134900. Mr. Almerbati's work was supported by King Fahd University of Petroleum and Minerals through the PhD scholarship at Duke University.

Notice: This submission was sponsored by a contractor of the United States Government under contract DE-AC05-00OR22725 with the United States Department of Energy. The United States Government retains and the publisher, by accepting the article for publication, acknowledges that the United States Government retains a non-exclusive, paid-up, irrevocable, world-wide license to publish or reproduce the published form of this manuscript, or allow others

to do so, for United States Government purposes. The Department of Energy will provide public access to these results of federally sponsored research in accordance with the DOE Public Access Plan (http://energy.gov/downloads/doe-public-access-plan).

\section{References}

[1] A. Bejan, Convection Heat Transfer, Wiley, New York, 2013, Chapter 3.

[2] R. K. Shah, A. L. London, Laminar Flow Forced Convection in Ducts, Academic, New York, 1978.

[3] T. Bello-Ochende, J.P. Meyer, J. Dirker, Three-dimensional multi-scale plate assembly for maximum heat transfer rate density, Int. J. Heat Mass Transfer 53 (2010) 586.

[4] C. Amador, A. Gavriilidis, P. Angeli, Flow distribution in different microreactor scale-out geometries and the effect of manufacturing tolerances and channel blockage, Chem. Eng. J. $101(2004) 379$. 
[5] A. J. Fowler, G. A. Ledezma, A. Bejan, Optimal geometric arrangement of staggered plates in forced convection, Int. J. Heat Mass Transf. 40 (1997) 1795.

[6] D.H. Kang, S. Lorente, A. Bejan, Constructal architecture for heating a stream by convection, Int. J. Heat and Mass Transfer 53 (2010) 2248.

[7] M. Ben Meftah, M. Mossa, Prediction of channel flow characteristics through square arrays of emergent cylinders, Phys. Fluids 25 (2013) 045102.

[8] Y. Chen, C. Zhang, M. Shi, J. Wu, Three-dimensional numerical simulation of heat and fluid flow in noncircular microchannel heat sinks, Int. Commun. Heat Mass Transfer 36 (2009) 917.

[9] M. R. Salimpour, M. Sharifhasan, E. Shirani, Constructal optimization of the geometry of an array of micro-channels, Int. Commun. Heat Mass Transfer 38 (2011) 93.

[10] L. A. O. Rocha, F. E. M. Saboya, J. V. C. Vargas, A comparative study of elliptical and circular sections in one- and two-row tubes and plate fin heat exchangers, Int. J. Heat Fluid Flow 18 (1997) 247.

[11] M. I. Hasan, A. A. Rageb, M. Yaghoubi, H. Homayoni, Influence of channel geometry on the performance of a counter flow microchannel heat exchanger, Int. J. Thermal Sciences 48 (2009) 1607.

[12] P. Gunnasegaran, H. A. Mohammed, N. H. Shuaib, R. Saidur, The effect of geometrical parameters on heat transfer characteristics of microchannels heat sink with different shapes, Int. Commun. Heat Mass Transfer 37 (2010) 1078.

[13] Y. S. Muzychka, E. Walsh, P. Walsh, Simple models for laminar thermally developing slug flow in noncircular ducts and channels, J. Heat Transfer 132 (2010) 111702. 
[14] A. A. Alfaryjat, H. A. Mohammed, N. M. Adam, M. K. A. Ariffin, M. I. Najafabadi, Influence of geometrical parameters of hexagonal, circular, and rhombus microchannel heat sinks on the thermohydraulic characteristics, Int. Commun. Heat Mass Transfer 52 (2014) 121.

[15] H. A. Mohammed, P. Gunnasegaran, N. H. Shuaib, Influence of channel shape on the thermal and hydraulic performance of microchannel heat sink, Int. Commun. Heat Mass Transfer 38 (2011) 474 .

[16] T.C. Hung, T.S. Sheu, W.M. Yan, Optimal thermal design of microchannel heat sinks with different geometric configurations, Int. Commun. Heat Mass Transfer 39 (2012) 1572.

[17] Y. Sui, C.J. Teo, P.S. Lee, Y.T. Chew, C. Shu, Fluid flow and heat transfer in wavy microchannels, Int. J. Heat Mass Transfer 53 (2010) 2760.

[18] M. Dehghan, M. Daneshipour, M. S. Valipour, R. Rafee, S. Saedodin, Enhancing heat transfer in microchannel heat sinks using converging flow passages, Energy Convers. Manag. 92 (2015) 244.

[19] COMSOL Multiphysics User's Guide, Version 4.3, COMSOL AB., 2012. 


\section{Figure captions}

Figure 1 Three designs of flow channels embedded in a square cross section.

Figure 2 The variation of fluid flow resistance for different flow channels, represented by area factor $\phi$, of square arrays, (a) square and (b) circular flow channel.

Figure 3 Velocity and temperature profiles of a flow channel embedded in square solid.

Figure 4 The mean temperature of the fluid stream which flows through hot contacting walls.

Figure 5 The variation of overall thermal resistance with area factor $\phi$, (a) square flow channel and (b) circular flow channel.

Figure 6 The overall thermal resistance versus the fluid flow resistance of(a) square flow channels, (b) circle flow channels.

Figure 7 Flow channels embedded in a triangular cross section.

Figure 8 The flow resistance variation for triangular arrays with the area factor $\phi$, (a) triangle flow channel and (b) circular flow channel.

Figure 9 For triangular cross-section; the overall thermal resistance versus area factor $\phi$.

Figure 10 The results of fluid flow resistance and thermal resistance for the triangular and circular flow channels embedded in triangle cross section.

Figure 11 Square and triangle arrays with the same flow length and mass flow rate per unit of cross-section area. 
Figure 1

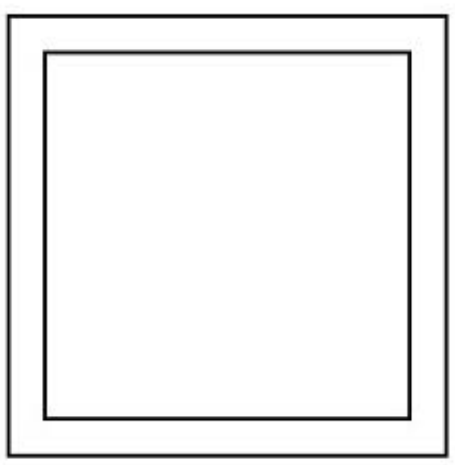

(a)

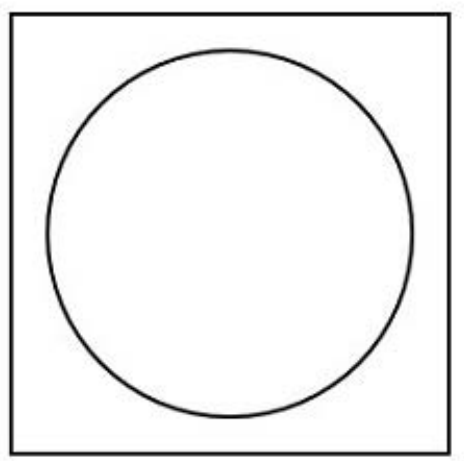

(b)

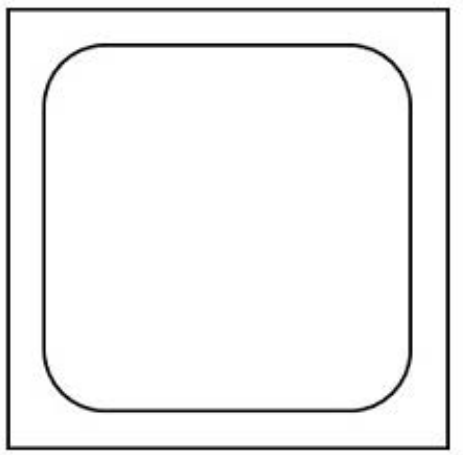




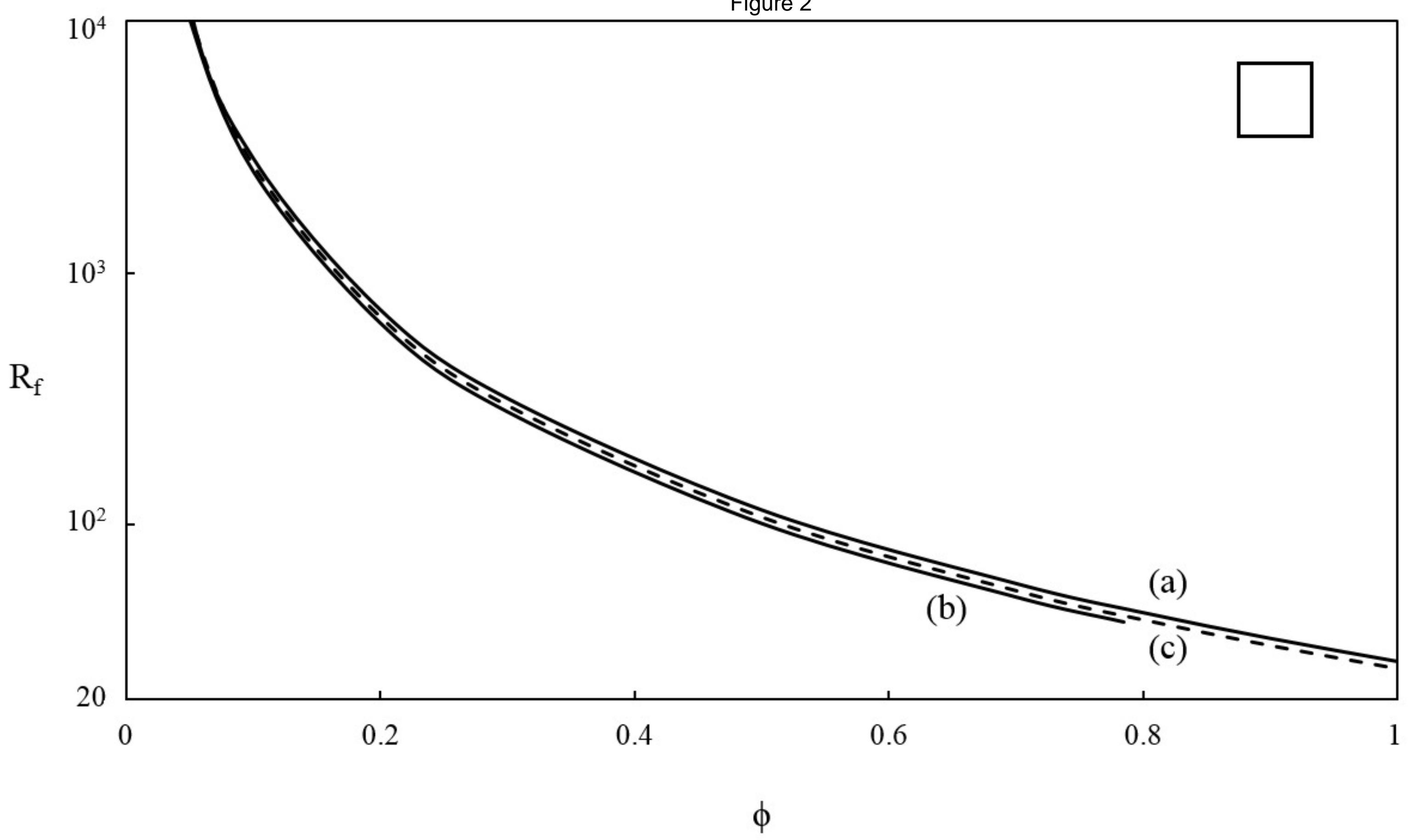


Figure 3

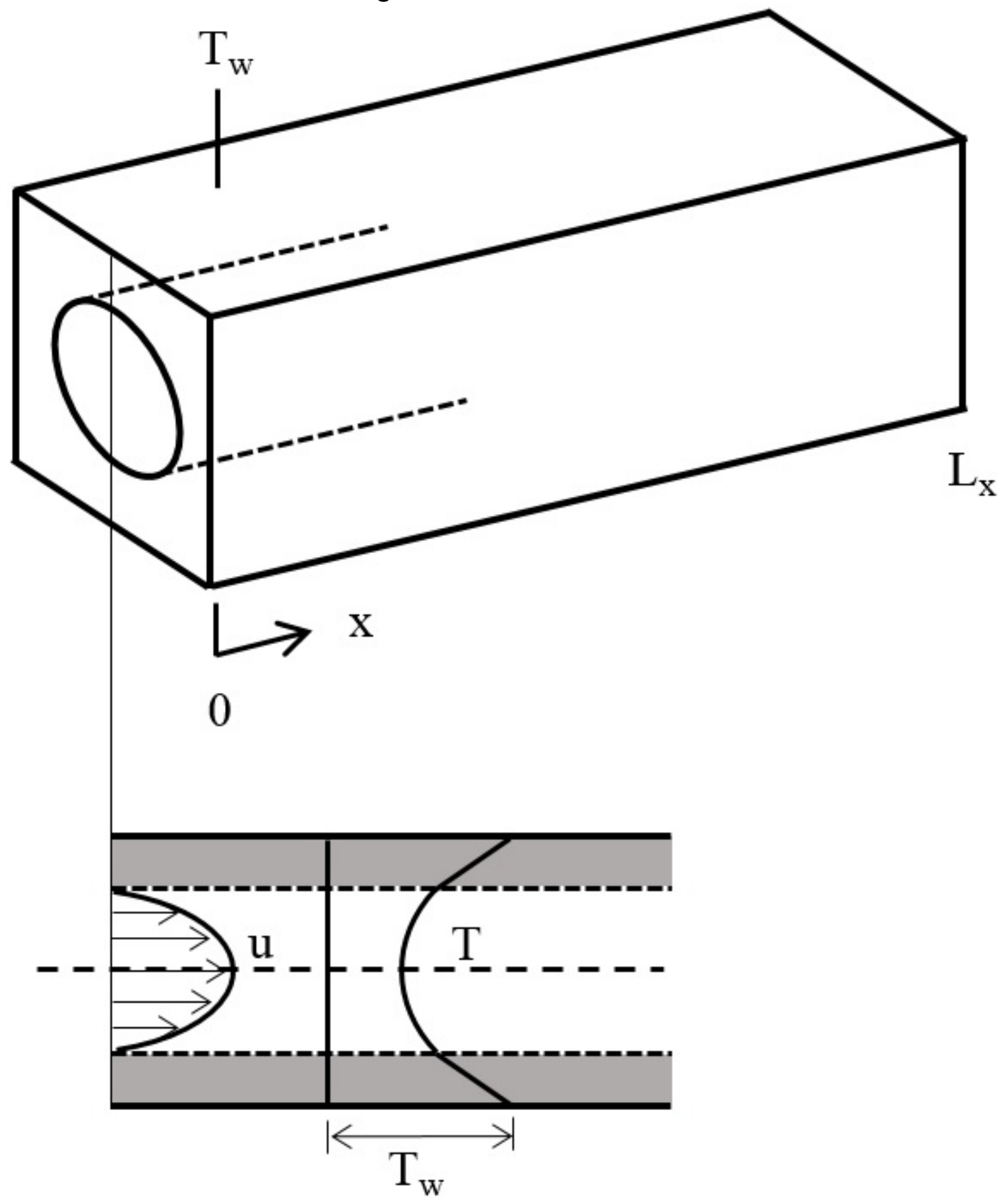


Figure 4

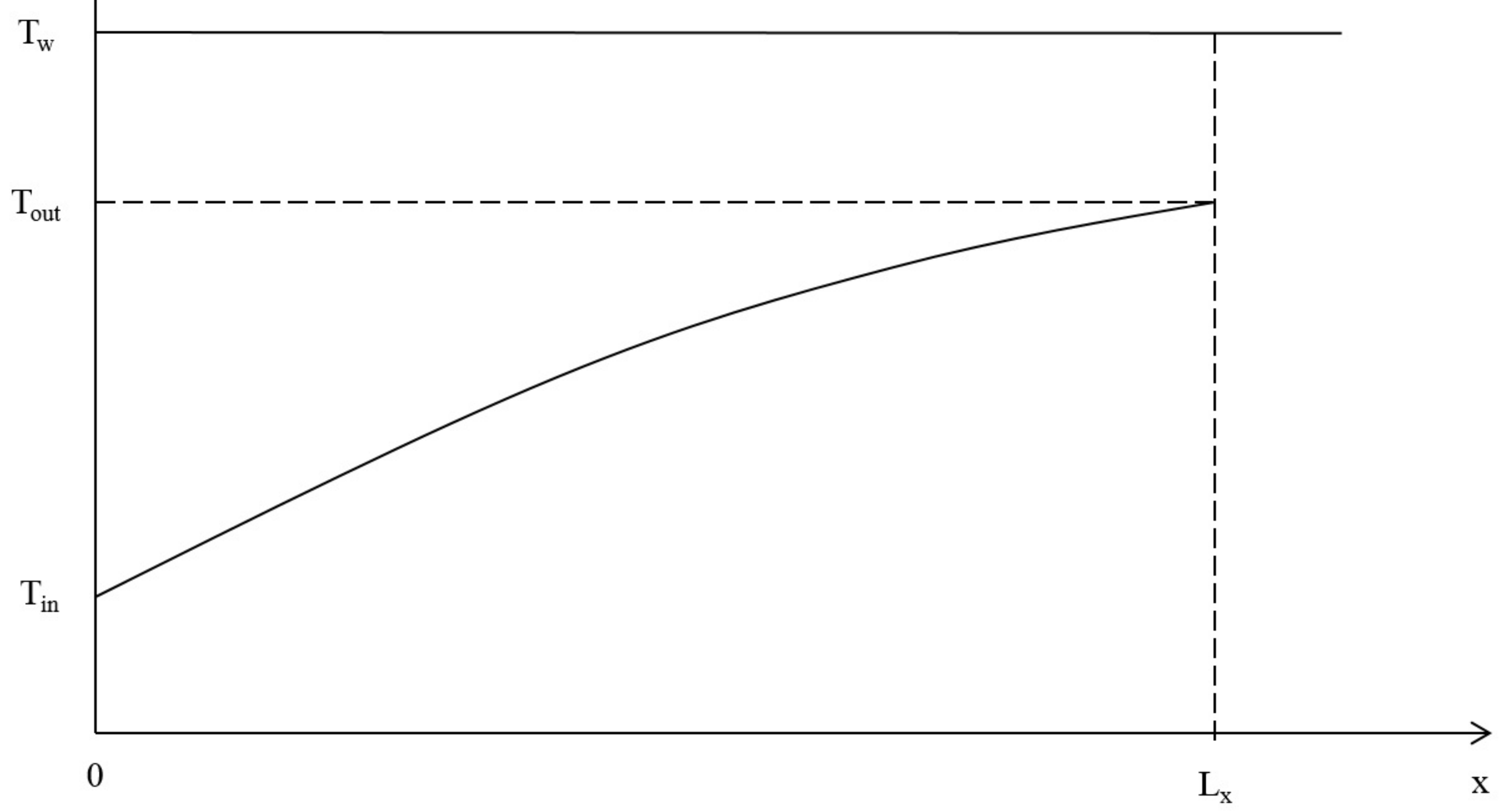




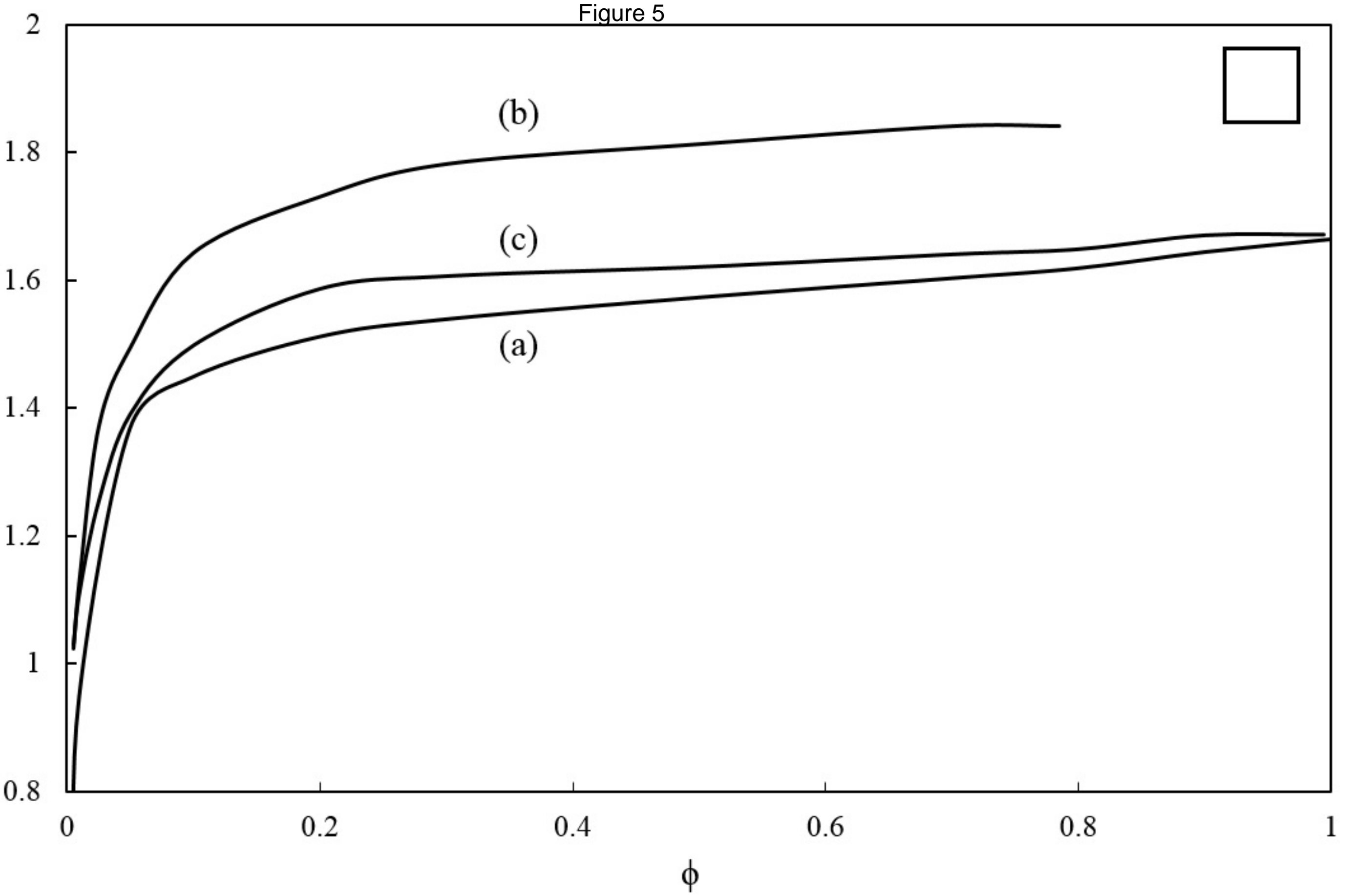


Figure 7

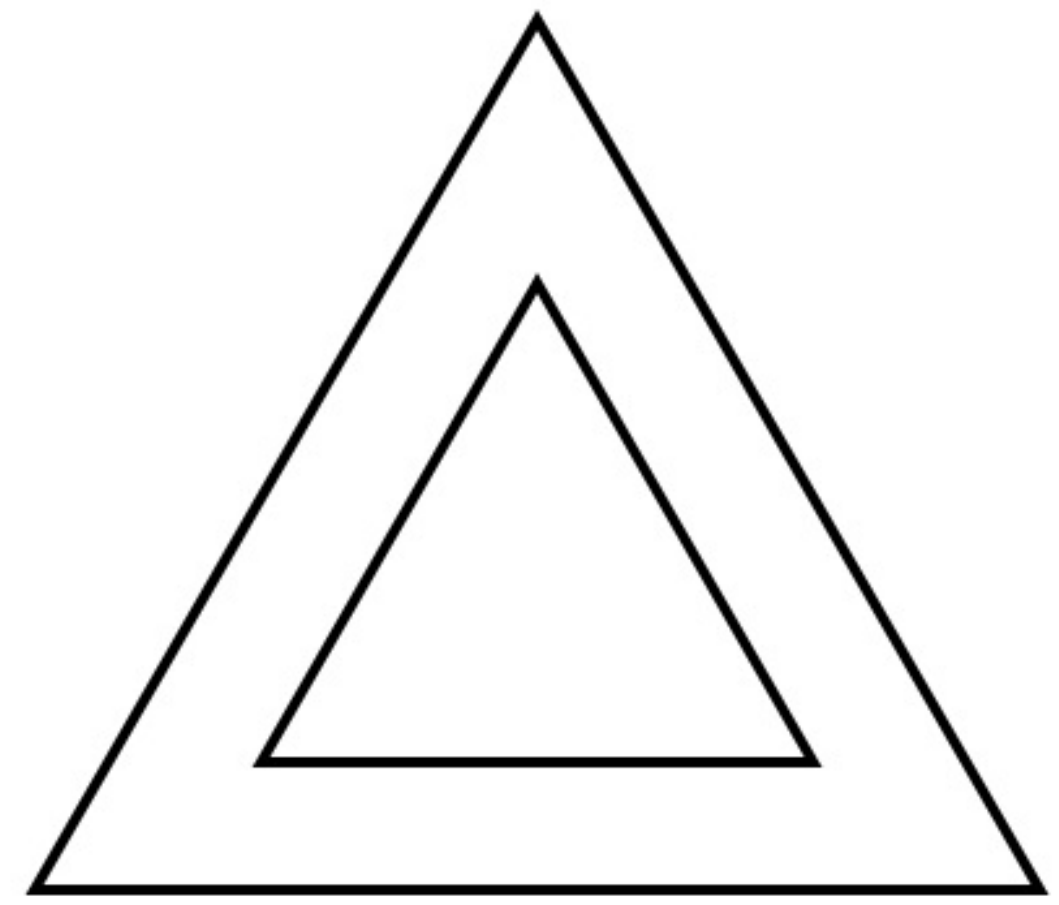

(a)

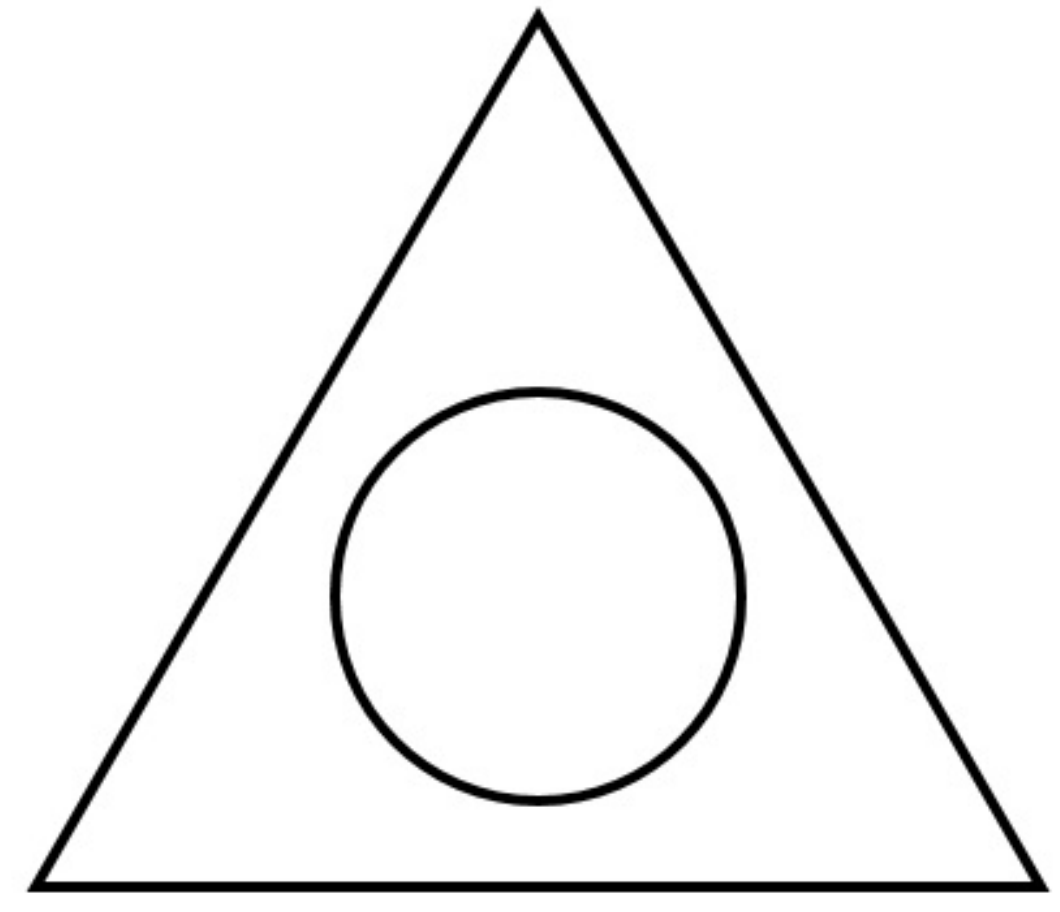

(b) 


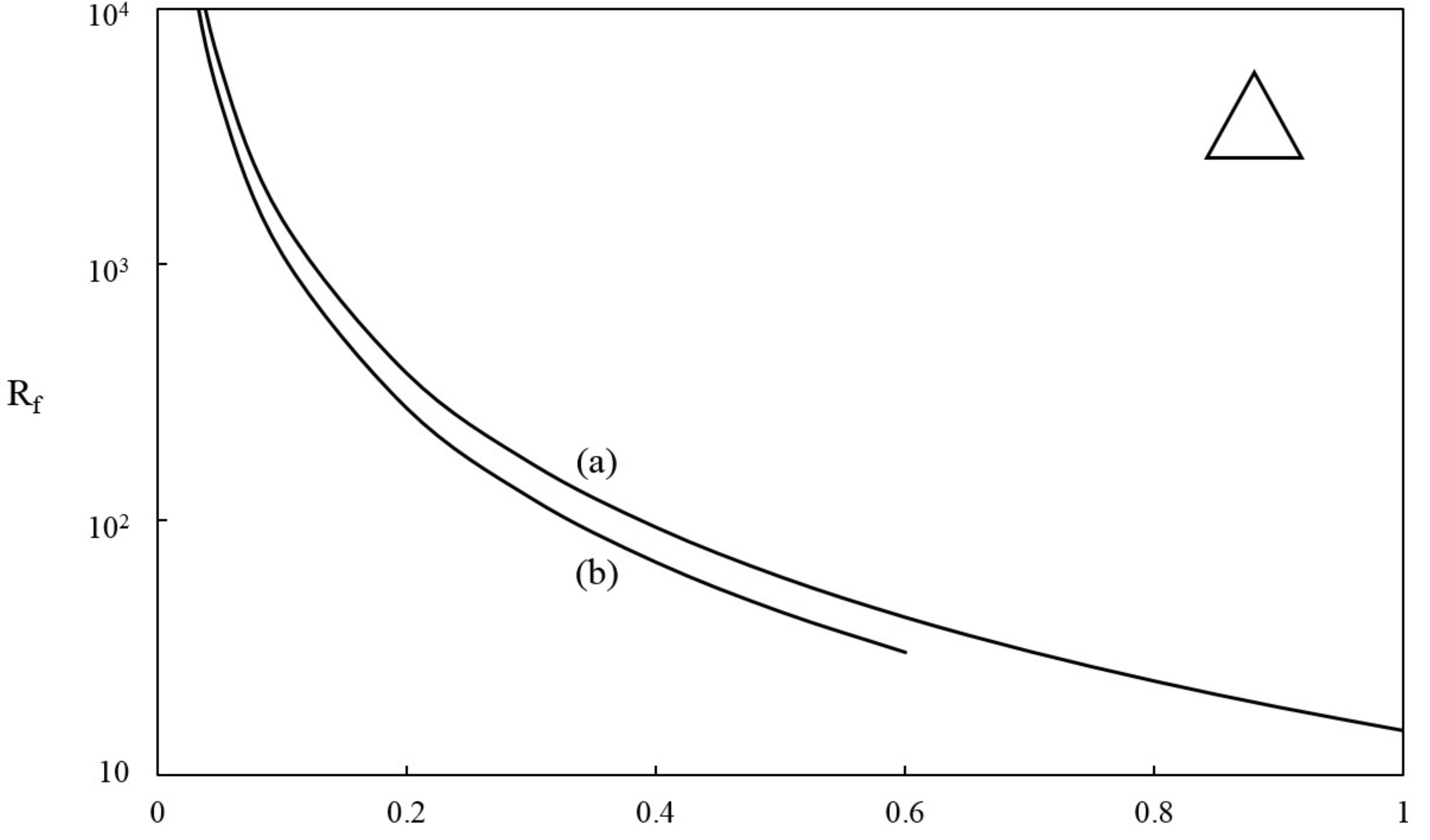

Figure 8 


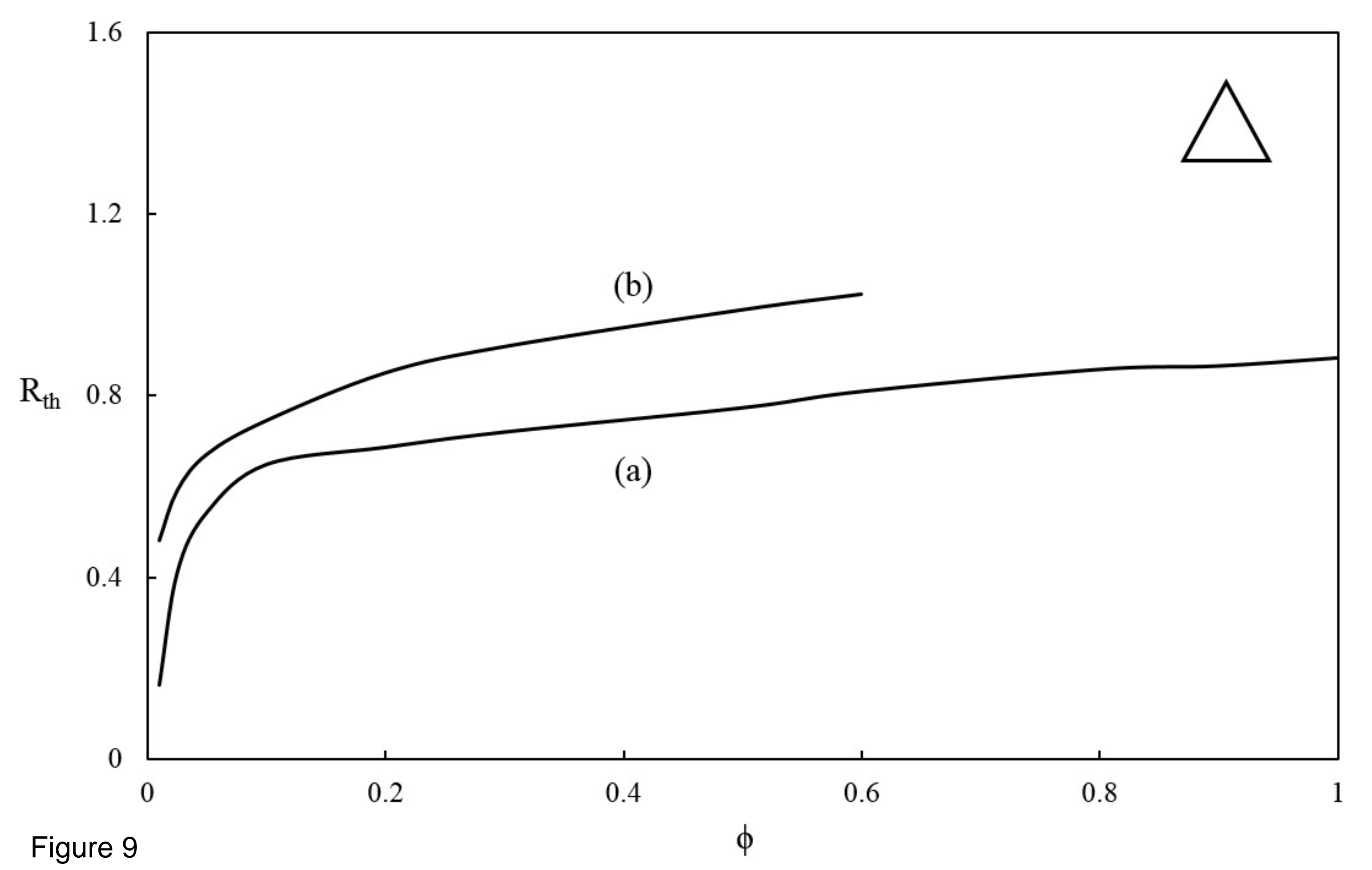




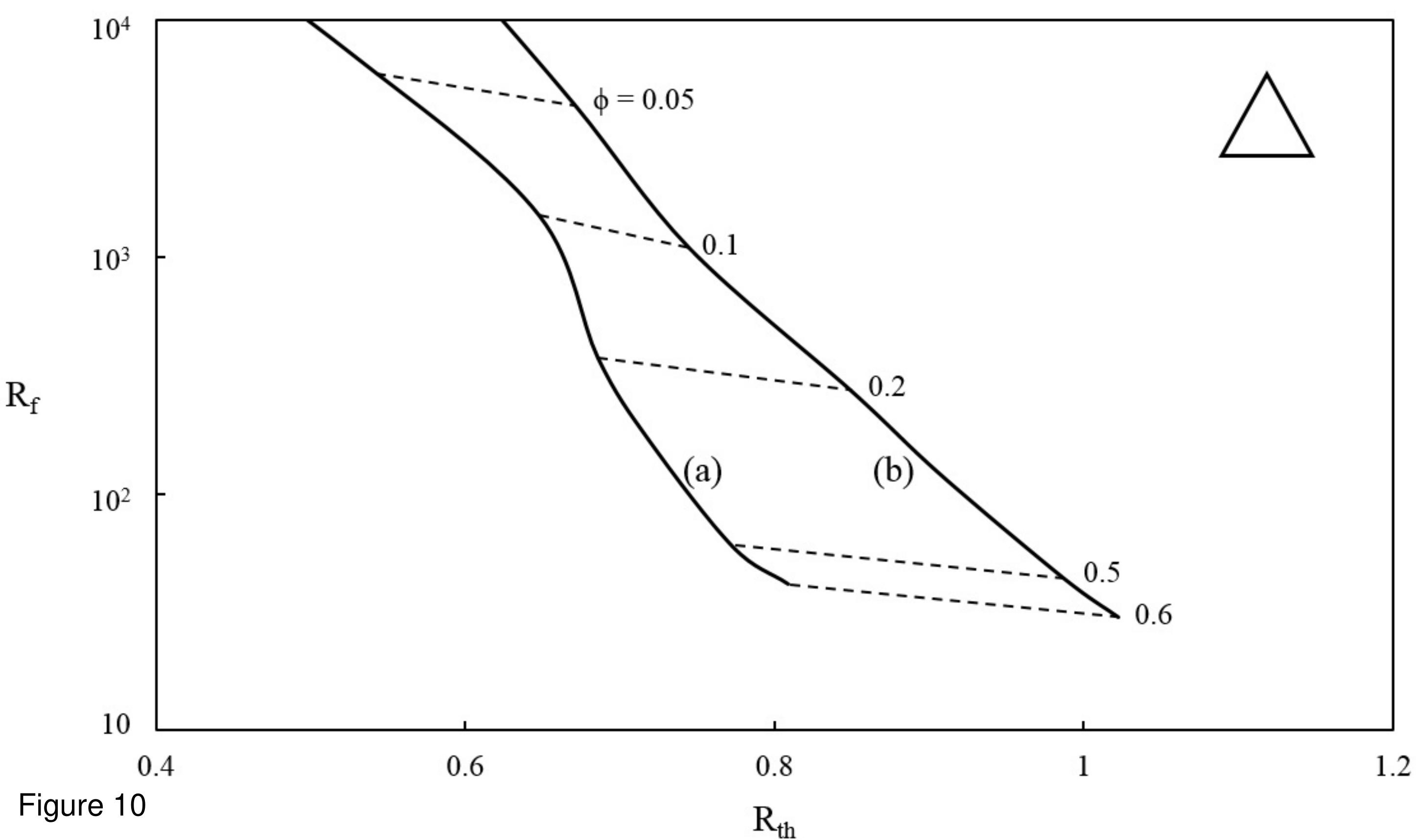


